\section{'Cover-up culture' blamed as officials miss budget hearing}

Washington. Two US congressional hearings planned to discuss inconsistencies in the Clinton administration's science budget were postponed last week after the sudden withdrawal of the administration officials who were due to testify.

The hearings would have allowed Republican congressmen to question administration officials about the apparent contradiction between budget projections from the White House Office of Management and Budget (OMB), which imply steep cuts in science funding, and the administration's public pledges to maintain its investment in science.

Robert Walker (Republican, Pennsylvania), chair of the Science Committee in the House of Representatives, which organized the hearings, said that the withdrawal was "one more sign of the culture of cover-up" at the White House. He said he would subpoena witnesses if necessary so that the hearings could take place.

Walker said that officials from OMB and Neal Lane, the director of the National Science Foundation (NSF), who were due to testify on 26 June, as well as Dan Goldin, the administrator of the National Aeronautics and Space Administration (NASA), who was to testify at a second hearing on 17 July, had contacted him "within a few hours" of each other to say that they could not attend. Lane and Goldin said they had prior engagements. But the OMB declined to testify at all, said Walker.

The Department of Energy was also believed to be reluctant to send anyone to the hearings, due to focus on assessments made by the American Association for the Advancement of Science (AAAS) of the effect of the Clinton budget projections on science spending (see Nature 380, 572; 1996). The first witness was to be Al Teich, head of science policy at the AAAS.

The AAAS has noted that the administration is projecting steep cuts in NASA, NSF and Department of Energy research spending in 1998, 1999 and 2000. But officials of each agency have said that they are not actually planning such deep cuts. The administration is deeply divided on the issue, and officials at the Department of Energy and NASA say privately that OMB projected the cuts without consulting them.

"We think it is very serious when you have administration officials speaking out of both sides of their mouths on this issue," says Walker. "They should be able to say what they think of the AAAS assessment." He says that the hearings would take place this month or, if necessary, in August, and that the committee may subpoena OMB officials to ensure their participation.

\title{
NSF braves threat to abolish social sciences directorate
}

Washington. The US National Science Foundation (NSF) has established a committee to find a new director for its social sciences directorate, despite the wishes of some powerful congressmen that the directorate should be abolished.

The NSF is seeking a successor to Cora Marrett, who returns this month to her sociology chair at the University of Wisconsin, Madison. But the price of the NSF's defiance became clear last week when the House of Representatives passed an amendment to an appropriations bill that would slash the agency's administrative budget by almost one-tenth.

The amendment was proposed by Robert Walker (Republican, Pennsylvania), chairman of the Science Committee, and passed despite the opposition of Jerry Lewis (Republican, California), who chairs the appropriations subcommittee responsible for NSF funding. The amendment would strip $\$ 9$ million from the NSF's $\$ 120$-million administrative budget.

Agency officials say it could result in compulsory lay-offs of up to 120 of the NSF's 1,200 headquarters staff in October, when the appropriations bill takes effect. This could pose serious difficulties for the agency, which funds most non-biomedical university research in the United States. Supporters of the agency say it is one of the most efficient in the federal government, spending only 4 per cent of its budget on administration. But Science Committee members, including Walker and Vernon Ehlers (Republican, Michigan), who spoke in favour of the amendment, are said to be angry with the agency for several reasons.

One is its failure to act on the committee's recommendation that the number of NSF directorates should be cut from seven to six. A provision to do this has been approved twice by the House of Representatives, but has not passed into law. Social sciences, which is the youngest and smallest of the seven directorates, would be the probable casualty of such an adjustment.

But Neal Lane, the director of the NSF, has vigorously defended the social sciences directorate. According to Marrett, the directorate has established social science disciplines as "central" to the NSF since its foundation in 1989

The Walker amendment transfers the $\$ 9$ million from administration to the NSF's research account. But another successful amendment to the bill took $\$ 13$ million away from that account to pay benefits to military veterans.

Colin Macilwain

\section{Italian bill sets out recruitment reforms}

Rome. Italian universities would be able to select new faculty members from a government-approved list - rather than having to accept candidates allocated to them by the ministry of education and research - under a radical set of new rules being proposed by the new minister, Luigi Berlinguer.

In a bill presented to the cabinet last week, Berlinguer argues that the current system of academic appointment should be abandoned. Winners of the concorsi, large national competitions that take place every few years, are at present allocated to a university - usually not of their choice - by the ministry in Rome. The system is widely criticized for its lack of both efficiency and transparency, the latter being seen as allowing appointments to be made on the basis of personal connections rather than merit (see Nature 378, 228; 1995).

The draft law proposes that the concorsi should continue but that they should take the form of 'procedure di abilitazione'. This means that, like the German Habilitation system, they should be used only to establish whether candidates are sufficiently skilled in teaching and research to be considered for university professorships and associate professorships. Judging committees should include foreigners - a new concept in Italy - while scientific achievement would, for the first time, be assessed "using indicators recognized by international scientific organizations".

Universities would hold separate local competitions for posts as they became vacant, and these would be open to those who have successfully passed the national competition. Candidates would be assessed by committees comprising local and external academics. But the competitions would be closed to those already employed at the university concerned. This, says Berlinguer, would introduce more movement into the university system, and also reduce the influence of personal connections.

Dario Braga, an associate professor of chemistry at the University of Bologna, and a member of the Association for Research and Academic Culture, which has pressed for university reform for several years, says that Ber-linguer's proposals are "a big step forward towards honest recruitment".

Alison Abbott 